Observatório de
Inovação do Turismo

Revista Acadêmica

ISSN 1980-6965
BRASIL

\title{
A disponibilidade da força de trabalho e sua relação com os serviços de alimentação: a percepção dos gestores de bares e restaurantes de Campinas-SP
}

\author{
Availability of workforce and its relationship with food services: Campinas \\ bars and restaurants managers' perception
}

\author{
Paulo Cesar Peres Pontara \\ Djair Picchiai \\ Tiago Zanett Albertini
}

\section{Resumo:}

Objetiva-se com este artigo analisar a percepção dos gestores de bares e restaurantes de Campinas-SP em relação à disponibilidade da força de trabalho do profissional garçom. As empresas pesquisadas são associadas ao Convention \& Visitors Bureau do município, e o procedimento adotado foi qualitativo e quantitativo. Representantes do trade turístico direcionaram a investigação inicial, descritiva e exploratória. Em seguida, gestores dos bares e restaurantes opinaram com questionário específico (escala Likert), e o conteúdo resultante foi submetido a testes para validação e cálculo do coeficiente de Cronbach. Nas análises, os resultados foram apresentados em frequências e estratificados por categorias de empresa, com ênfase em micro e pequenas empresas (MPEs). Sugere-se uma revisão na forma de relacionamento entre empregador e profissional garçom visto haver indícios da precarização. Os resultados associam-se à economia no mercado de trabalho, à posição socioprofissional que o garçom ocupa, na percepção dos gestores.

Palavras-chave: gestores, força de trabalho, disponibilidade, garçons, bares, restaurantes, micro e pequenas empresas (MPEs)

O artigo foi recebido em 21/3/2013 e foi aceito em 12/8/2013. 


\section{Abstract:}

The objective of this paper is to analyze the perception of managers of bars and restaurants in Campinas-SP regarding the availability of workforce professional of waiter. The surveyed are associated with the Convention \& Visitors Bureau of the county and the procedure adopted was qualitative and quantitative. Representatives of the tourism trade directed an initial descriptive and exploratory research. Then, managers of bars and restaurants opined with specific questionnaire (Likert scale) and the resulting contents subjected to tests for validation and calculation based on Cronbach's coefficient. In the analysis, the results were presented as frequencies and stratified by type of business, with emphasis on small and medium enterprises (SME's). It is suggested a revision in the form of relationship between employer and professional waiter as there is evidence of instability. The results are associated with the economy in the labor market, social and professional position to which the waiter holds, under the perception of managers.

Key words: managers, manpower, availability, waiters, bars, restaurants, small and medium enterprises (SME's)

\section{Introdução}

O município de Campinas é um dos principais centros industriais do estado e do País (IPEA, 2011). Segundo Souza e Garcia (1999) apud Szapiro (2003) e Villaschi (2005), as empresas que se instalaram na região, antes da década de 1990, tinham interesses associados à facilidade de acesso às instituições de Pesquisa \& Desenvolvimento (P\&D) e à educação. Após a segunda metade daquela década, a opção das empresas pela região ocorria, além do interesse pelas instituições de $P \& D$ e educação, por causa da disponibilidade de recursos de força de trabalho e do sistema bem desenvolvido de estradas - uma vantagem competitiva de logística. O turismo de negócios, por exemplo, despontou como a principal atividade no entorno da exploração do setor de turismo, assim como as atividades de lazer. Brito e Fontes (2002, p. 40 e 41) definem que, no turismo de negócios, a captação de eventos:

[...] é um conjunto de ações que tem como objetivo principal a conquista de eventos para o núcleo receptor. A execução deste trabalho envolve três atividades fundamentais: análise das condições do núcleo

para sediar eventos; avaliação dos tipos de eventos que podem ser realizados; definição da estratégia de captação de eventos para o núcleo.

Ao analisarem-se as condições do núcleo para sediar os eventos, devem-se considerar os seguintes aspectos: existência de espaço para 
a realização de eventos; capacidade hoteleira; transportes turísticos e infraestrutura de apoio e serviços, tais como: atrações turísticas e gastronomia diversificada, o que envolve bares e restaurantes.

Nos registros do Ministério do Turismo (MTUR, 2010), ressalva-se a existência de desafios a serem superados entre "destinos turísticos" e "disponibilidade e qualidade da força de trabalho". Segundo Lovelock e Wright (2002, p. 347), a demanda flutuante no setor de turismo é perceptível em muitas empresas que prestam serviços a clientes individuais ou empresariais e ocasiona estragos no uso eficiente dos recursos produtivos: uma estratégia crucial dos serviços.

De acordo com o Documento Referencial do Ministério do Turismo,

[...] é importante destacar ainda que ações implementadas para atenuar a sazonalidade dos fluxos turísticos, como investimentos em centros de convenções, programas promocionais para períodos de baixa ocupação, etc., exercem, indiretamente, impacto positivo na efetividade da qualificação profissional, por permitirem maior fixação da força de trabalho (MTUR, 2010, p. 33).

Segundo o MTur (2010, p. 29), o turismo continua sendo "uma importante fonte na economia mundial, pois representa uma parte significativa dos empregos e do produto interno bruto global". Conforme a Organização Mundial do Turismo (OMT) apud MTur (2010), o turismo é responsável pela geração de 6 a $8 \%$ do total de empregos no mundo, além de ser uma das atividades econômicas que demanda o menor investimento para a geração do trabalho. Dessa forma, o MTur (2010, p. 29) destaca:

[...] a dimensão econômica do turismo pode ser avaliada por meio da metodologia de Con-tas Satélites do Turismo, conforme recomendação da OMT, que delimita os setores da economia relacionados com o setor.

Esses setores, denominados Atividades Características do Turismo ACTs, constituem a base para a avaliação do mercado de trabalho do turismo, com base em dados da Relação Anual de Informações Sociais RAIS, do Ministério do Trabalho e Emprego, que registram as ocupações formais no País. De acordo com a metodologia da OMT e os dados da RAIS, o mercado formal de trabalho nas Atividades Características do Turismo - ACTs, no Brasil, passou de 1,71 milhão de pessoas empregadas, em 2002, para 2,27 milhões de pessoas empregadas em 2008, o que repre-senta um crescimento da ordem de $32,70 \%$ em seis anos. No ano de 2008, esse número correspondeu a 5,76 \% do total de empregos formais acumulados no País (MTUR, 2010c, p. 29). 
Conforme Ferraro (2012), o turismo de negócios movimentou cerca de R \$ 1 bilhão (US\$ 588 milhões) na região metropolitana de Campinas (RMC) em 2011, ao mesmo tempo em que foram realizados em torno de seis mil eventos, atraindo aproximadamente 1,5 milhão de visitantes para as cidades da região. Além de o município ter infraestrutura de hotéis, bares, restaurantes, shoppings, entre outros, destaca-se pela logística como um fator competitivo privilegiado, o que pode ser percebido pelas excelentes rodovias, a proximidade com a capital São Paulo e o Aeroporto de Viracopos, cuja ampliação, após o anúncio da privatização (fevereiro de 2012), faz parte do planejamento estratégico do governo brasileiro e da INFRAERO (FERRARO, 2012).

De acordo com Diniz et al. (2010, p. 2), entre as profissões preteridas socialmente, destaca-se a de garçom - uma das atividades que mais geraram postos de trabalho na década de 1990. O enfoque conferido a essa profissão dá-se não só pela já apontada importância socioeconômica, mas também pela incipiência de estudos na Administração que priorizem esses trabalhadores e o setor em que atuam. Diniz et al. (2010, p. 2) destacam a necessidade e a importância de voltar-se o olhar para profissões historicamente marginalizadas, inclusive no âmbito acadêmico, o que há de contribuir para o questionamento das formas de exclusão e dos inúmeros preconceitos observados na realidade social.

Diante desses fatos que colocam em evidência o município de Campinas, pergunta-se: qual é o risco desse cenário ocorrer nesse município? Objetiva-se, pois, com esta pesquisa analisar a percepção dos gestores de bares e restaurantes de Campinas-SP em relação à atual disponibilidade da força de trabalho de garçons e a relação com os serviços de alimentação.

O referencial teórico será construído com conceitos a respeito do turismo e da força de trabalho; da economia dos mercados de trabalho, explorando as forças de oferta, demanda e equilíbrio; da força de trabalho no setor de serviços de alimentação e a relação com a qualidade.

Como delimitação, as empresas participantes são associadas ao CRC \& VB (2009) e estão presentes no guia oficial do turismo de negócios da cidade de Campinas. As empresas foram classificadas em microempresa (ME), pequena empresa (PE) e média empresa (MED). Ressalve-se que este trabalho é uma síntese da dissertação de mestrado que abordou a mesma temática, defendido em fevereiro de 2012. Assim, o questionário original com cinquenta proposições aqui é delimitado a 33 análises. 


\section{Metodologia}

Trata-se de uma pesquisa qualitativa e quantitativa. Os procedimentos metodológicos da pesquisa foram divididos e ordenados em três fases. A primeira consistiu na construção do referencial teórico relacionado com variáveis objetos do estudo. Na segunda fase, realizaram-se entrevistas com profissionais, especialistas do trade turístico e instituições de ensino, ocorridas entre dezembro/2010 e janeiro/2011, para o delineamento da investigação de campo a ocorrer posteriormente. Assim, foram selecionados um representante do setor hoteleiro; um do setor gastronômico; um de Campinas e região Convention \& Visitors Bureau; um de instituição pública de ensino; e um de cada uma das duas instituições privadas de ensino. Basearam-se os critérios de seleção dos representantes na capacidade de absorção e capacitação da mão de obra (representantes dos setores hoteleiro e gastronômico); interlocução e acessibilidade com os associados do CRC \& VB; formação de mão de obra no nível profissionalizante (ensino público) e percepção da demanda em relação a cursos na área de turismo e hotelaria (ensino privado). A prática adotada foi a da pesquisa/ação, um tipo de pesquisa social com base empírica que é concebida e realizada em estreita associação com uma ação em que os pesquisadores e os participantes representativos da situação ou do problema estão envolvidos no modo cooperativo ou participativo (THIOLLENT, 1985). Os representantes do trade também auxiliaram na construção do questionário de escala Likert, opinando sobre a viabilidade das questões a serem consideradas, conforme Tabela 1 (Apêndice). Para a construção do questionário, Meireles (2010) destaca que os participantes registram suas opiniões sobre a viabilidade ou não das questões do instrumento de pesquisa de campo. Na terceira fase, ocorreu a coleta dos dados com origem nas respostas dos gestores de bares e restaurantes, entre os meses de junho e julho de 2011. Segundo Antunes e Dantas (2010), na escala Likert, os participantes são solicitados não só a concordarem ou discordarem das afirmações, mas também a informarem seus graus de concordância/discordância, o que, nesta pesquisa, variou em uma escala de 1 a 5. Para a validação do constructo, utilizou-se a função Reliability Analysis do software SPSS (Version 11.x), que calculou o coeficiente de Cronbach, resultando em parâmetros estatísticos de confiabilidade dos dados. Posteriormente, analisaram-se as proposições selecionadas quanto aos aspectos gerais e estratificadas por categoria de empresas. 


\section{Referencial teórico}

\subsection{O SETOR DO TURISMO}

Segundo Palomo (1991) apud Beni (2001, p. 34), o turismo pode ser considerado uma atividade econômica em razão de o ato de viajar ser um ato humano, de a recreação ser uma atividade desenvolvida por indivíduos ou grupos, de os deslocamentos serem ações que compreendem gastos e receitas, de o consumo de bens e serviços ser uma ação econômica e de a geração de riqueza, por meio de um processo produtivo, ser também tipicamente uma ação econômica.

De acordo com Fernandes e Coelho (2002, p. 13), a crescente atividade turística tem a própria dinâmica e justificativa social, por isso não pode ser concebida como um fato meramente conjuntural ou simplesmente passageiro.

A Organização Mundial do Turismo (OMT, 2011) assim define o turismo:

[...] um fenômeno social, cultural e econômico que implica livre circulação de pessoas para países ou lugares fora de seu ambiente habitual para fins pessoais ou de negócios/profissional. Essas pessoas são chamadas de visitantes (turistas ou excursionistas, residentes ou não residentes), e o turismo tem a ver com suas atividades [...]

Cabe ressaltar que a atividade do turismo, em alguns destinos, não representa uma atratividade significativa para a mão de obra e sua alocação permanente, forçando-a na busca de alternativas. O MTur (2010) destaca a importância das ações para atenuar a sazonalidade dos fluxos turísticos, como investimentos em centros de convenções, programas promocionais para períodos de baixa ocupação para que exerçam, indiretamente, impacto positivo na efetividade da qualificação profissional e permitir maior fixação da força de trabalho, ou seja, uma sinergia entre os atores do trade turístico, ou dos stakeholders.

Segundo Hansas (1998) apud Barbieri e Cajazeira (2008), o conceito de stakeholder é visto como uma teoria que frequentemente se confunde com o que é denominado como teoria empírica da administração, em que o sucesso da empresa em termos financeiros pode ser mais facilmente alcançado se atendidos os interesses de acionistas, fornecedores, trabalhadores, clientes e outras partes interessadas.

Barbieri e Cajazeira (2008) destacam que o estado deve reconhecer o direito de toda pessoa ter a possibilidade de ganhar a vida mediante um trabalho livremente escolhido ou aceito e deve tomar medidas apropriadas para salvaguardar esse direito. Essas medidas devem incluir orientação e formação técnica profissional, a elaboração de programas, normas técnicas apropria- 
das para assegurar um desenvolvimento econômico, social e cultural constante e pleno emprego produtivo em condições que salvaguardem nos indivíduos o gozo das liberdades políticas e econômicas fundamentais. De acordo com os autores, por meio do Pacto Internacional dos Direitos Econômicos, Sociais e Culturais, o estado deve reconhecer o direito de toda pessoa ter condições justas e favoráveis que assegurem, especialmente, uma remuneração que proporcione, no mínimo (os principais), a todos os trabalhadores:

a) salário equitativo e uma remuneração igual por um trabalho de igual valor, sem qualquer distinção;

b) condições de trabalho seguras e higiênicas;

c) iguais oportunidades para serem promovidos, no trabalho, à categoria superior que thes corresponda apenas a considerações de tempo, de trabalho e de capacidade; e

d) descanso, lazer, limitação razoável das horas de trabalho e férias periódicas remuneradas, assim como remuneração dos feriados.

\subsection{ECONOMIA DOS MERCADOS DE TRABALHO}

Segundo Mankiw (2001), as empresas produzem bens e serviços usando vários insumos, como trabalho, terra e capital, denominados fatores de produção. As famílias são as proprietárias dos fatores de produção e consomem todos os bens e serviços produzidos pelas empresas. Famílias e empresas interagem em dois tipos de mercados: nos de bens e serviços, em que as famílias são compradoras e as empresas, vendedoras, e nos mercados de fatores de produção, em que as famílias são vendedoras e as empresas, compradoras.

As necessidades humanas, infinitas e caracterizadas por privações e desejos, os recursos produtivos, meios para produção de bens e serviços, e as técnicas de produção, consideradas como conhecimento de transformar recursos em bens e serviços, são elementos essenciais de uma atividade econômica. Os recursos produtivos também apresentam características peculiares, como a escassez, dada a limitação em quantidade, e a versatilidade múltipla, conforme utilização e aplicação. Esses recursos são combináveis entre si quando ajustados em proporções variadas. Com base na movimentação de oferta versus demanda e de produção versus consumo, surgem os maiores problemas econômicos de uma sociedade, que se resumem em o quê e o quanto produzir e como e para quem produzir (FERNANDES; COELHO, 2002, p. 111-115).

Da mesma forma que recursos produtivos, como capital, terra, trabalho, tecnologia, capacidade gerencial, devem ser geridos da forma mais racional possível, com vistas à maior eficiência e economia, o turismo também demanda atenção para evitar ociosidade ou perda, como um apartamento de hotel não ocupado, uma mesa desocupada no restaurante, um assento livre no ônibus ou no avião, ou, caso contrário, um hotel com $100 \%$ de ocupação e, assim, sucessivamente 
(FERNANDES; COELHO, 2002, p. 52). Segundo os autores, a demanda flutuante para os serviços, como hotéis e restaurantes, é um problema que ronda uma enorme fatia de empresas que prestam serviços a clientes individuais ou empresariais, o que ocasiona estragos no uso eficiente dos recursos produtivos.

\subsubsection{Demanda de força de trabalho}

Conforme Beni (2001, p. 146), a demanda é a quantidade de um bem ou serviço que os consumidores desejam e podem comprar a um dado preço em um dado tempo. É determinada pelo preço do bem ou serviço submetido à análise, pelo valor de outros bens ou serviços substitutivos ou complementares. Os mercados de trabalho são governados pelas forças de oferta e demanda, porém são diferentes da maioria de outros mercados porque a demanda de força de trabalho é derivada: muitos serviços da força de trabalho, em vez de serem produtos finais prontos para serem usufruídos pelos consumidores, são insumos para a produção de outros bens e serviços.

O entendimento da demanda de força de trabalho dá-se pela perspectiva das empresas que contratam e utilizam-na para produzir bens ou serviços. Pode-se entender, então, que a determinação dos salários de equilíbrio ocorre com o elo entre a produção de bens e a demanda de força de trabalho (MANKIW, 2001, p. 398). Segundo o autor, a curva de demanda por trabalho pode deslocar-se ao ser considerada a influência que o preço (aumento ou queda) do bem ou serviço pode exercer diretamente no salário do trabalhador, ou mesmo do quanto o progresso tecnológico está associado ao aumento da produtividade do trabalho.

\subsubsection{Oferta de trabalho}

Segundo Beni (2001, p. 146), a oferta é entendida como a quantidade de um bem ou serviço que chega ao mercado por um dado preço em um determinado período de tempo. Depende do preço e das condições em que é produzida, também denominada função de produção, resultante da tecnologia utilizada e dos preços dos insumos necessários.

A curva de oferta de trabalho mostra como as decisões dos trabalhadores, em relação ao tradeoff entre trabalho e lazer, reagem a uma variação nesse custo de oportunidade. O tradeoff entre trabalho e lazer está por trás da curva de oferta de trabalho: quanto mais horas o ser humano passa trabalhando, menos horas tem para o lazer ou dedicação ao passatempo preferido. Ao mesmo tempo, aplica-se a esse tema o conceito de que o custo de algo é aquilo do qual se abre mão para obtê-lo (MANKIW, 2001, p. 404).

Assim como a demanda, Mankiw (2001, p. 405) destaca que a curva de oferta de trabalho também está sujeita a deslocamentos, como a variação da quantidade de trabalho que as pessoas 
desejam oferecer a qualquer salário dado. Outro fator é percebido na mudança nas oportunidades alternativas, ou seja, a oferta em qualquer mercado de trabalho depende das oportunidades disponíveis em outros mercados.

\subsubsection{Equilíbrio do mercado de trabalho}

Segundo Mankiw (2001, p. 406), o salário é responsável por atender a duas condições simultaneamente: ajustar-se para equilibrar oferta e demanda por força de trabalho; e ser igual ao valor do produto marginal do trabalho. Quando o mercado está em equilíbrio, cada empresa compra tanta força de trabalho quanto considera lucrativo o salário de equilíbrio, seguindo a regra de maximização de lucro, contratando trabalhadores até que o valor do produto marginal do trabalho seja igual ao salário. Nesse caso, o salário deve igualar-se ao produto marginal do trabalho, uma vez que a demanda e a oferta tenham atingido o equilíbrio (MANKIW, 2001, p. 406).

Mankiw (2001, p. 407) também destaca que, na iminência de um possível deslocamento da oferta de força de trabalho, decorrente do fenômeno de imigração, por exemplo, quando ela aumentar, talvez em decorrência dos novos trabalhadores, o salário de equilíbrio há de cair. Com esse salário inferior, a empresa pode contratar mais trabalhadores, de modo que o emprego aumente. Na iminência de um deslocamento da demanda de força de trabalho, Mankiw (2001, p. 408) afirma que, quando a demanda de força de trabalho aumenta, talvez em decorrência de um aumento de preço do produto da empresa, o salário e o emprego aumentarão.

\subsection{A FORÇA DE TRABALHO No SETOR DE SERVIÇOS E A RELAÇÃo COM A QUALIDADE}

Segundo Barros e Mendonça (1997, p. 11), o setor de serviços pessoais, entre os quais se destacam a hospedagem e a alimentação, entre outras atividades consideradas básicas, apresenta as seguintes características: emprega uma proporção de trabalhadores semelhante à indústria da construção civil em conjunto, mas, por outro lado, apenas metade daquela para os demais serviços; tem expandido o número de postos de trabalho tanto em termos absolutos, quanto em relação ao próprio tamanho, a taxas superiores às da indústria de transformação e da construção civil em conjunto, mas inferiores em termos absolutos e semelhantes em termos relativos à expansão dos demais serviços; e os serviços pessoais têm dado uma contribuição para a geração de postos de trabalho no Brasil.

Segundo Lovelock e Wright (2002, p. 108), a qualidade e a satisfação do cliente de serviços decorrem do serviço desejado em relação ao serviço adequado. Entende-se por serviço desejado o nível de qualidade de serviço que um cliente acredita que deva ser entregue; e por serviço 
adequado o nível mínimo de serviço que um cliente aceitará sem ficar insatisfeito, atendendo a suas necessidades básicas. Os autores afirmam também que empresas que conseguem fornecer serviço de alta qualidade são eficientes na escuta de seus clientes e, principalmente, de seus funcionários: em particular os que estão em contato direto com os clientes.

Conforme Berni (2006), a tendência à terceirização da atividade econômica no Brasil não deve perder o ímpeto, o que significa, por exemplo, que alimentos industrializados poderão deixar de ser consumidos em casa, crescendo a demanda por serviços de bares e restaurantes. Segundo Whiteley (1992) apud Las Casas (2008, p. 26 e 27), as empresas que aplicam em qualidade geralmente colocam o cliente em primeiro lugar, investem em seu pessoal, fazem com que as equipes trabalhem, nunca parem de aprender e também nunca se dispersem. Aperfeiçoar serviços é aperfeiçoar o ser humano, o que é possível com treinamento, uma das atividades essenciais para a prestação de serviços de qualidade, além de outros fatores, como motivação, condições que a empresa oferece e também nível de relacionamento da administração com seus subordinados (LAS CASAS, 2008, p. 119).

3.3.1 A força de trabalho no setor de serviços de alimentação e a relação com a qualidade

Segundo Lashley e Morrison (2004, p. 379 e 380), a administração do trabalho relacionado com hospitalidade, que consiste no bem receber, seja em hotéis ou restaurantes, é problemática por diversas razões. Os autores destacam:

[...] os funcionários têm apenas uma frouxa fidelidade em relação à organização em que trabalham, pois suas habilidades são relativamente fáceis de serem transferidas para outras organizações e, em qualquer caso, os clientes, por meio de gorjetas, fornecem uma grande parte de seus ganhos. Assim, os funcionários são considerados dotados de baixo status e baixa especialização, o que torna difícil

fazê-los genuinamente hospitaleiros mediante os tipos de controle geralmente utilizados com os funcionários operativos.

A qualidade da hospitalidade, dada pelo atendimento do funcionário desse setor, é influenciada diretamente pelo tratamento que o funcionário recebe do empregador, assim como pelo modo como é tratado pelo cliente (LASHLEY; MORRISON, 2004, p. 380). Forte (1982) apud Lashley e Morrison (2004, p. 379) destaca: "no setor de serviços, o ingrediente mais importante no produto é a pessoa. A qualidade de nosso pessoal determina a qualidade do serviço que prestamos aos clientes e, desse modo, nosso sucesso no mercado".

Lashley e Morrison (2004, p. 380) ressalvam que, por consequência, os funcionários do atendimento, além de serem meios de proporcionar hospitalidade, também são conside- 
rados custos empresariais, havendo sempre um compromisso na busca do equilíbrio entre a quantidade de hospitalidade fornecida e o valor que os clientes estão dispostos a pagar.

De acordo com Costa (2004) apud Diniz et al. (2010, p. 2), a pequena complexidade e o conhecimento exigidos por algumas atividades acabam por minar o status de determinadas profissões, estigmatizando-as como de baixo valor ou de menor importância para a sociedade. O baixo reconhecimento conferido às profissões braçais resulta em um fenômeno nomeado invisibilidade social, em que há o desaparecimento do sujeito ante outros membros da sociedade, seja pela indiferença, seja pelo preconceito. De acordo com o autor, o enfoque conferido a essa profissão dá-se não só pela já apontada importância socioeconômica, mas também pela incipiência de estudos na administração que priorizem esses trabalhadores e o setor em que atuam. Diniz et al. (2010, p. 2) também citam, ainda, a necessidade e a importância de voltar-se o olhar para profissões historicamente marginalizadas, inclusive no âmbito acadêmico, o que irá contribuir para o questionamento das formas de exclusão e dos inúmeros preconceitos observados na realidade social.

\subsection{CONCEITO E CLASSIFICAÇÃO DAS EMPRESAS}

Segundo o Serviço Brasileiro de Apoio às Empresas (SEBRAE, 2010), as micro e pequenas empresas (MPEs) constituem, aproximadamente, 97,00\% das empresas atuantes no Brasil. Para a classificação são adotados critérios específicos, tais como o tamanho (porte), a receita bruta anual e a quantidade de funcionários. No critério quantidade de funcionários no setor de serviços, consideram-se microempresas (MEs) as que têm até nove funcionários. Nas pequenas empresas (PEs), a quantidade de funcionários estabelecida determina entre dez e 49 funcionários.

Recentemente, os artigos 10, 3o, 17, 18, 18-A, 19, 20, 25, 30, 31, 41 e 68 da Lei Complementar n.o 123, de 14 de dezembro de 2006, foram alterados pela Lei Complementar n.․ 139, de 10 de novembro de 2011. Assim, no art. 3., lê-se:

I. no caso da microempresa aufira, em cada ano-calendário, receita bruta igual ou inferior a $R \$ 360.000,00$ (trezentos e sessenta mil reais); e

II. no caso da empresa de pequeno porte aufira, em cada ano-calendário, receita bruta superior a $R \$ 360.000,00$ (trezentos e sessenta mil reais) e igual ou inferior a $R \$ 3.600 .000,00$ (três milhões e seiscentos mil reais). 


\subsection{Contexto brasileiro e Região metropolitana de Campinas}

Segundo Bacha (2004), no Brasil, existem diversas fontes de dados sobre emprego e salários na economia e que não são, necessariamente, compatíveis entre si. Como exemplo, cita o Instituto Brasileiro de Geografia e Estatística (IBGE) em que se realizam, com periodicidade quase decenal, os censos demográficos sobre a população residente. Ao mesmo tempo, no IBGE, também se realiza a Pesquisa Mensal de Emprego (PME) restrita às regiões metropolitanas de Recife, Salvador, Belo Horizonte, do Rio de Janeiro, de São Paulo e Porto Alegre. No caso específico de São Paulo, os dados são apurados pelo Departamento Intersindical de Estatística e Estudos Socioeconômicos (DIEESE) e pela Federação da Indústria do Estado de São Paulo (FIESP). Nessas pesquisas, avaliam-se as taxas de desemprego na região metropolitana de São Paulo, as pessoas ocupadas e o salário médio da indústria paulista (BACHA, 2004, p. 210).

Na região metropolitana de Campinas, as relações de trabalho entre garçons e contratantes são regidas pela Consolidação das Leis Trabalhistas (CLT) e acrescidas das instruções da Convenção Coletiva de Trabalho do Sindicato dos Empregados no Comércio Hoteleiro de Campinas e Região. Conforme a Convenção de 2012, na cláusula segunda, pertinente à abrangência, prevê-se a inclusão de bares e restaurantes, considerando-os como categorias abrangidas.

Atualmente, o valor do salário normativo para início de atividade estabelece o piso de $R \$ 760,00$ (setecentos e sessenta reais) que se enquadra na tabela de estimativas de gorjetas. Na Convenção, estipula-se que o pagamento de valores a título de estimativa de gorjeta, deve ser corrigido nos mesmos moldes dos salários, com a anotação na Carteira de Trabalho e Previdência Social (CTPS), bem como os direitos decorrentes. Os valores das gorjetas são determinados na Convenção que se baseia na quantidade de funcionários do estabelecimento: um a cinco funcionários, $R \$ 84,50$; seis a vinte funcionários, $R \$ 116,00$; e acima de vinte funcionários, $\mathrm{R} \$ 126,10$ de gorjeta. 


\section{Características da pesquisa}

\subsection{UNIVERSO E AMOSTRA}

Bares e restaurantes do CRC \& VB totalizam 33 empresas, entre microempresas (MEs), pequenas empresas (PEs) e médias empresas (MEDs), conforme Tabela 2. Dos 33 associados, obteve-se a colaboração de 26 , o que representou $78,79 \%$ de amostra do universo pesquisado. Das 26 empresas, em 24, informou-se que 653 funcionários compõem o negócio, sendo 277 garçons $(42,41 \%)$.

Tabela 2. Estratificação das empresas/Critério quantidade de funcionários

\begin{tabular}{|ccccc|}
\hline PORTE DA & $\begin{array}{c}\text { UNIVERSO DA } \\
\text { PESQUISA }\end{array}$ & PERCENTUAL & $\begin{array}{c}\text { AMOSTRA DA } \\
\text { PESQUISA }\end{array}$ & PERCENTUAL \\
Microempresa & 7 & $21,21 \%$ & 4 & $15,38 \%$ \\
Pequena empresa & 23 & $69,70 \%$ & 20 & $76,92 \%$ \\
Média empresa & 3 & $9,09 \%$ & 2 & $7,69 \%$ \\
\hline TOTAL & 33 & $100,00 \%$ & $\mathbf{2 6}$ & $\mathbf{1 0 0 , 0 0 \%}$ \\
\hline
\end{tabular}

Fonte: Elaborada pelos autores.

4.2 Teste: Alpha de Cronbach /Reliability Statistics

Segundo Maroco e Garcia-Marques (2006), pelo índice alpha avaliam-se os itens que contribuem, uniformemente, para a soma não ponderada do instrumento, variando numa escala de 0 a 1, o que também se conhece por consistência interna da escala. Assim, o alpha pode ser interpretado como coeficiente médio de todas as estimativas de consistência interna que seriam obtidas se todas as divisões possíveis da escala fossem feitas.

O resultado do teste aplicado na pesquisa revelou um alpha de Cronbach de 0,789, o que demonstrou uma confiabilidade apropriada às análises propostas. 


\section{Principais resultados e análises}

5.1 Percepção do Gestor sobre a eConomia dos mercados de trabalho: Demanda

Nas proposições de 1 a 5 , investigaram-se questões pertinentes à demanda por trabalho e a qual tipo se refere. Percebe-se que a procura por trabalho nas micro e pequenas empresas (MPEs) ocorre com frequência, com forte tendência à carga horária parcial. Ao mesmo tempo, 80,00\% dos gestores das MPEs demonstram preocupação no que diz respeito a esse tipo de procura. Percebe-se, também, que o preço do cardápio (proposições 20 e 21) tem uma relação menos significativa $(50,00 \%)$ em relação aos impactos que a gorjeta tem nos salários (85,00\%). Em muitos estabelecimentos, a gorjeta tornou-se opção, porém com uma acentuada prática de indução ao cliente no que diz respeito ao pagamento. $\mathrm{Na}$ proposição 40, destaca-se que o gestor se preocupa com a reposição de força de trabalho, com destaque nas MEs (100,00\%) e nas PEQs (70,00\%). Porém, nas MEDs destacou-se em 100,00\% uma discordância com a proposição, ou seja, a reposição de força de trabalho não é fator preocupante.

\subsection{Percepção do gestor sobre a eConomia dos mercados de trabalho: oferta}

Nas proposições de 6 a 10, investigaram-se questões pertinentes à oferta de trabalho e a qual tipo se refere, integral ou parcial. Percebe-se que a oferta nas MEs e MEDs ocorre em 100,00\% dos respondentes, enquanto, nas PEQs, a frequência é menor, o que representa $65,00 \%$. Nas proposições 11,12 , e 14, investigaram-se questões pertinentes à oferta de trabalho quanto aos aspectos da influência das oportunidades alternativas em outros setores, da fácil absorção da força de trabalho em outras atividades e da influência do tradeoff trabaIho x lazer como fator de tomada de decisão do trabalhador. Os resultados sinalizaram, nas três categorias de empresas, a percepção dos gestores de que as oportunidades surgidas em outros setores têm sido responsáveis pela migração da força de trabalho para atividades mais atrativas, inclusive com tradeoff mais favorável ao trabalhador. Os resultados das MEs (75,00\%), das MEDs (100,00\%) e das PEQs (95,00\%) contribuíram de forma considerável para essas análises. Na proposição 29 , demonstrou-se que nem todos os gestores têm a percepção da necessidade de o trabalhador distinguir o seu trabalho da necessidade do lazer. Nessa proposição, apresentou-se, nas MEs (50,00\%), a neutralidade das respostas, assim como, nas PEQs (40,00\%), o que pode representar uma fragilidade nas relações entre empregador e empregado. Na proposição 37, reforçou-se que a influência do tradeoff "quantidade 
de trabalho" em relação à "quantidade de lazer" incide diretamente na tomada de decisão do trabalhador, o que pode ser percebido nas MEs $(75,00 \%)$, nas MEDs $(50,00 \%)$ e nas PEQs $(55,00 \%)$.

\subsection{Percepção do gestor sobre a economia dos mercados de trabalho: equilíbrio}

Nas proposições 13, 17 e 18, investigaram-se questões pertinentes à função do salário como uma força que representa o equilíbrio nos mercados entre a oferta de trabalho e a demanda por trabalho. O gestor percebeu que existem salários e benefícios mais atrativos à força de trabalho do que em outros setores, porém destaca que, na média, essa percepção representou um pouco mais da metade das respostas, realçando as MEs $(50,00 \%)$ e as PEQs (65,00\%) dos resultados. As MEDs (50,00\%) discordaram dessa proposição, o que pode sugerir que, nas empresas maiores, os salários são melhores. Os gestores das três categorias (média de 55,00\%) destacaram haver sim políticas de salários e benefícios e serem elas capazes de reter a força de trabalho (média de 70,00\%), com destaque para as PEQs (85,00\%).

Assim, o fator salário pode ser uma determinante na interpretação do desequilíbrio percebido nas relações entre a força de trabalho e os empregadores. Por exemplo, se a demanda por trabalhadores aumentou em outros setores, por suposição, significa que melhores salários e benefícios estão sendo oferecidos. Assim, a movimentação pode resultar na migração da força de trabalho específica de um setor para outro, e que se há de aproveitar as qualificações preexistentes na força de trabalho.

\subsection{PercepÇÃo do gestor sobre a força de trabalho e sua relação Com o mercado de TRABALHO NOS SERVIÇOS DE BARES E RESTAURANTES: SERVIÇO E QUALIDADE}

Nas proposições 36, 39 e 44, destacam-se questões pertinentes à adaptação da força de trabalho em relação às regras, normas e condutas; ao nível de investimento em treinamento e desenvolvimento; à presença de obstáculos socioculturais nos futuros profissionais a serem treinados e aos resultados das pesquisas de satisfação direcionadas aos clientes. Nas MEs e nas PEQs, destacou-se, com resultados iguais de 50,00\%, que a força de trabaIho apresenta dificuldades em adaptar-se às regras, bem como se evidenciaram deficiências relacionadas com questões de base sociocultural percebidas nos candidatos, que constituem obstáculos na formação do futuro profissional. Essa análise também pode ser corroborada com a da proposição 40 , em que se enfatiza a grande dificuldade que bares e restaurantes enfrentam na reposição de funcionários, conforme as MEs (100,00\%), as MEDs (100,00\%) e as PEQs (70,00\%) que contribuíram para esses resultados. 
Da mesma forma, nas proposições 45 e 46, reforçaram-se essas análises, pois se enfatizou que a força de trabalho tem representado riscos associados ao negócio quanto aos aspectos de atrasos, demoras e falhas operacionais no atendimento, com destaque para as MEs (75,00\%), as MEDs (50,00\%) e as PEQs (65,00\%) dos resultados da P45. Percebe-se, assim, que as ações associadas ao recrutamento, ao treinamento, ao próprio perfil da força de trabalho podem ser as variáveis que explicam esse alto grau de risco percebido. Nas proposições 47, 48 e 49, investigou-se a percepção do gestor em relação à importância das instituições técnicas de ensino e das de ensino superior, quanto aos aspectos determinantes da formação; à consciência das tendências do novo perfil profissional e de sua essencialidade ou caráter fundamental no processo de formação.

Nas MEs (50,00\%) e nas PEQs (40,00\%), há concordância de que as instituições de ensino são importantes na capacitação da força de trabalho para o negócio, assim como, em resultados similares, há consciência das tendências do novo perfil a ser capacitado. Destaca-se, porém, que o grau de concordância é relativamente baixo quanto à proposta das instituições de ensino como agentes stakeholders. Como reforço a essa análise, na proposição 49, destaca-se que, nas MEs (75,00\%) e nas PEQs (35,00\%), há um concerto de que as instituições de ensino não são fundamentais no processo de formação da força de trabalho, enquanto resultados contrários a essa proposição foram constatados nas MEDs (100,00\%).

No que diz respeito às pesquisas de satisfação, nas MEs, nas MEDs e nas PEQs, há relatos da presença de resultados positivos no parecer dos clientes, porém, nas proposições 45 e 46, contradizem-se esses resultados. Não há evidências de que todos os pesquisados praticam e aplicam pesquisas de satisfação entre seus clientes.

\subsection{Percepção do gestor sobre a força de trabalho e sua relação com o mercado de TRABALHO NOS SERVIÇOS DE BARES E RESTAURANTES: PROFISSÃO, SOCIEDADE E TURISMO}

Nas proposições 30 a 35, abordaram-se questões baseadas no referencial teórico e investigaram-se a percepção do gestor em relação à posição social e profissional da força de trabalho com o seu trabalho e a própria valorização e importância. Destacou-se a percepção do quanto a função de garçom é de fácil aprendizagem; do quanto é considerada braçal; do quanto é discriminada socialmente; e do quanto é despercebida. De acordo com o entrevistado E3, a própria força de trabalho, quando inserida nos cursos de qualificação, conceitua-se como uma função de subemprego, o que, somado às jornadas de trabalhos aos sábados, domingos e feriados, ressalva que essa profissão não caracteriza uma atratividade de carreira, e sim uma forma de ganhos adicionais gerados nos finais de semana. 
No que diz respeito à função de garçom ser de fácil aprendizagem, existe uma concordância considerável nas MEDs (100,00\%) e nas PEs (75,00\%), enquanto nas MEs (50,00\%), com resultados iguais, houve discordância, pois posicionaram-se como neutras em relação à proposição. Quanto à função ser considerada um trabalho braçal, nas MEDs, (100,00\%) houve concordância quanto à proposição, enquanto nas PEQs (60,00\%), discordância. Nas MEs (50,00\%), com similaridade de resultados, ficou-se entre a discordância e a neutralidade da proposição.

No que se refere à função ser "discriminada socialmente", nas MEs (50,00\%), considerou-se essa possibilidade, enquanto nas MEDs (100,00\%) e nas PEQs (65,00\%) julgou-se o contrário dessa proposição. Contribuindo para tal análise, nos resultados da proposição, sugere-se que o garçom é uma função que passa despercebida, e destaca-se, nas MEs (50,00\%) e nas PEQs (60,00\%), discordância dessa afirmativa, enquanto nas MEDs (50,00\%) demonstra-se similaridade nos resultados de concordância e discordância.

Em relação à possibilidade de mudanças percebidas no perfil do profissional durante os últimos anos, existe uma concordância idêntica nas MEs e nas MEDs (100,00\%), enquanto nas PEQs (45,00\%) discordância dessa proposição. Ressalve-se, porém, que, nos resultados das MEs (100,00\%) e das PEQs (65,00\%), destaca-se a mudança de perfil do profissional e o fato de a mudança ter sido para pior. Pela resposta das MEDs (50,00\%), demonstra-se a similaridade entre discordância e concordância parcial.

Nas proposições 38, 42 e 43, investigaram-se a percepção do gestor em relação à importância do turismo em seu negócio e a ocorrência dessa interação com a força de trabalho. No primeiro critério, perceberam-se a proximidade e a similaridade nos resultados das MEs, das MEDs e das PEQs (50,00\%) e a variação entre a discordância e a concordância com a proposição, demonstrando certa indefinição e ambiguidade nas respostas. Da mesma forma, constataram-se, nas três categorias e na visão dos gestores, resultados pouco expressivos na capacidade de a força de trabalho distinguir os clientes residentes dos turistas, assim como, na pouca percepção para com a importância do turismo no negócio, sugerindo a falta de estratégias específicas de treinamento destinado ao atendimento de turistas. 


\section{Conclusão}

Na percepção dos gestores de bares e restaurantes em relação à disponibilidade da força de trabalho, pela óptica da demanda, reflete-se um cenário distorcido de falsos mitos considerados estratégicos para a efetividade e o funcionamento dos estabelecimentos. Esses mitos estão alicerçados na informalidade das vagas oferecidas, bem como nos salários, que para sua formação se baseiam fortemente na gorjeta, o que inicialmente poderia ser caracterizado como uma vantagem competitiva e/ou estratégica para o setor.

Esses mitos também podem refletir no atual momento de escassez da força de trabaIho ou na própria dificuldade de reposição das vagas. A formação do salário da categoria não se baseia em princípios básicos da economia, como a função do salário marginal. Da mesma forma, percebe-se, pelas variáveis da oferta, que outros setores, talvez não sujeitos a tantas oscilações ou sazonalidades, têm sido mais atrativos à migração da força de trabalho que busca, além de uma maior estabilidade e formalidade nas relações entre salários e benefícios. É preciso considerar que o próprio tradeoff de tomada de decisão entre trabalho e lazer é mais atrativo, retomando o direito a sábados, domingos e feriados, situação não característica ao setor de bares e restaurantes. Em parte da pesquisa, revelou-se que nem todos os gestores reconhecem o tradeoff trabalho versus lazer como uma variável de decisão do trabalhador. Por consequência, salários, benefícios e jornada de trabalho têm sido as variáveis de equilíbrio de outros setores que recepcionam ex-garçons, absorvendo-os facilmente por suas noções de língua estrangeira.

Os atuais candidatos apresentam, geralmente, dificuldades de adaptação, da mesma forma que são considerados obstáculos na fase de preparo e desenvolvimento para a função. Ficaram evidentes, também, a pouca influência e a reduzida importância que as instituições de ensino têm representado na formação da força de trabalho. Sugere-se que uma das interpretações que deva ser considerada com pertinência é a facilidade com a qual a função é apreendida pelos garçons. A possível causa, primeiramente atribuída ao atual perfil do profissional, e na tentativa de explicar os desafios do setor, retorna e é dividida com os gestores, que talvez subestimem e associem a atual fase a fenômenos externos, isentando-se de suas responsabilidades diretas. Nesse ponto de vista, é necessário que todos os stakeholders - no caso os empresários, o Poder Público, as instituições de ensino e até a própria sociedade mobilizem-se de forma organizada e conscientizem-se da atual situação, de suas efetivas atribuições e de como não têm tido repercussão ou efeito eficaz na tratativa desse problema. Para esta pesquisa é recomendável que o CRC \& VB assuma esse desafio de quebra de paradigma que envolve as relações das empresas com a força de trabalho, na busca de uma nova 
ordem ou formato para o setor, conscientizando os associados de que nem todas as vantagens competitivas herdadas são necessariamente vantagens competitivas. Dessa forma, haveria ações estratégicas inovadoras e inéditas destinadas ao setor de turismo, que paira sob a constante preocupação da força de trabalho como variável de risco. 


\section{Referências}

ANTUNES, F. H. C.; DANTAS, L. Sistematização do conhecimento declarativo em educação física escolar de 5. a a 8. a séries do ensino fundamental. Revista Brasileira de Educação Física e Esporte, São Paulo, vol. 24, n.o 2, jun. 2010. Disponível em: <http://www.revistasusp.sibi.usp.br/ scielo.php?script=sci_arttext\&pid=\$1807-55092010000200005\&lng=pt\&nrm=iso>. Acesso em: 26 dez. 2011, às 13h17min.

BARBIERI, J. C.; CAJAZEIRA, J. E. R. Responsabilidade social empresarial e empresa sustentável. São Paulo: Saraiva, 2008.

BARROS, R. P.; MENDONÇA, R. A absorção de mão de obra no setor de serviços. Dados, Rio de Janeiro, vol. 40, n.o 1, 1997. Disponível em: <http://www.scielo.br/scielo.php?script=sci_ arttext\&pid=S0011-52581997000100002\&Ing=en\&nrm=iso>. Acesso em: 26 dez. 2011, às 17h17min. http://dx.doi.org/10.1590/S0011-52581997000100002.

BENI, M. C. Análise estrutural do turismo. 6. ed. atual. São Paulo: SENAC, 2001.

BERNI, D. de A. Mudanças no padrão de uso da força de trabalho no Brasil entre 1949 e 2010. Nova Economia, Belo Horizonte, vol. 16, n.o 1, abr. 2006. Disponível em: <http://www.scielo.br/ scielo.php?script=sci_arttext\&pid=S0103-63512006000100004\&lng=en\&nrm=iso>. Acesso em: 28 dez 2010, às 21h23min. doi: 10.1590/S0103-63512006000100004.

BRASIL. Lei Complementar n. 139, de 10 de novembro de 2011. Disponível em: <http://www.planalto.gov.br/ccivil_03/leis/LCP/Lcp139.htm>. Acesso em: 8 dez. 2011, às 14h15min.

Lei Complementar n.o 10.406 de janeiro de 2002. Disponível em: <http://www.planalto. gov.br/ccivil_03/leis/2002/L10406.htm\#art966>. Acesso em: 8 dez. 2011, às 14h37min.

BRITO, J.; FONTES, N. Estratégias para eventos: uma ótica do marketing e do turismo. São Paulo: Aleph, 2002.

CRC \& VB. Relação dos associados dos bares e restaurantes. Campinas e Região Convention \& Visitors Bureau. Guia do profissional de eventos. 3. ed. 2007/2009. Disponível em: <http://www. visitecampinas.com.br/revista/index.html>. Acesso em: 23 jan. 2010, às 14h37min. Página 59 
Guia do profissional de eventos. Campinas e Região Convention \& Visitors Bureau. 3. ed. 2007/2009.

DINIZ, A. P. R.; SOUZA, M. M. P.; BARRETO, R. O. Ser garçom é isso tudo... não é apenas levar uma bandeja: as estratégias discursivo-identitárias dos garçons. In: ANPAD. VI Encontro de Estudos Organizacionais. Florianópolis-SC: ANPAD, maio 2010. CD-ROM.

FERNANDES, I. P.; COELHO, M. F. Economia do turismo: teoria \& prática. Rio de Janeiro: Campus, 2002.

FERRARO, T.; Agência Metropolitana de Campinas: turismo de negócios movimenta US\$ 588 miIhões. Disponível em: <http://www.agemcamp.sp.gov.br/index.php?option=com_content\&vi ew $=$ article\&id=1336\%3Aturismo-de-negocios-movimenta-us-588-milhoes\&catid=6\%3Armc-noticias\&lang=pt>. Acesso em: 14 mar. 2012, às 12h37min.

IBGE. Dados estatísticos do município de Campinas de 2010. Disponível em: <http://www.ibge.gov. br/cidadesat/topwindow.htm?1>. Acesso em: 15 jan. 2011, às 15h15min.

IPEA. PIB do estado de São Paulo. Disponível em: <http://www.ipea.gov.br/portal/index. php?option=com_content\&view=article\&id=12657\&catid=159\&ltemid=75>. Acesso em: 19 dez. 2011, às $2 \mathrm{~h} 4 \mathrm{~min}$.

LAS CASAS, A. L. Qualidade total em serviços. 6. ed. São Paulo: Atlas, 2008.

LASHLEY, C.; MORRISON, A. Em busca da hospitalidade: perspectivas para um mundo globalizado. Barueri-SP: Manole, 2004.

LOVELOCK, C.; WRIGHT, L. Serviços: marketing e gestão (Principles of service marketing and management). São Paulo: Saraiva, 2002.

MANKIW, N. G. Introdução à economia: princípios de micro e macroeconomia. 2. ed. Rio de Janeiro: Elsevier, 2001. 
MAROCO, J.; GARCIA-MARQUES, T. Qual a fiabilidade do alfa de Cronbach? Questões antigas e soluções modernas?. Laboratório de Psicologia, Lisboa-Portugal, vol. 4, n.o 1, p. 65-90, 2006 (Instituto Superior de Psicologia Aplicada, Portugal — ISPA).

MEIRELES, M.; SANCHES, C. Construção e validação de escala Likert. Disponível em: <www.profmeireles.com.br>. Acesso em: 28 dez. 2010.

MTUR. Turismo no Brasil 2011-2014. (2010) Disponível em: <http://www.copa2014.turismo.gov. br/export/sites/default/copa/noticias/todas_noticias/downloads_noticias/Turismo_no_Brasil_2011_-_2014.pdf>. Acesso em: 20 dez. 2010, às 20h43min.

OMT - Organização Mundial do Turismo. Glossário básico. Disponível em: <http://www.unwto. org/pdf/Understanding_Tourism-BasicGlossary_EN.pdf>. Acesso em: 19 dez. 2011, às 17h40min.

SEBRAE. Critérios e conceitos para classificação de empresas. Disponível em: <http://www.busca. sebrae.com. $b r /$ search? $q=$ como+classificar + micro+e+pequena + empresa\&spell=1\&output $=x$ ml_no_dtd\&client=web_um\&proxystylesheet=sebrae2\&lr=lang_pt\&sort=date\%3AD\%3AL\% 3Ad1\&entqr $=3 \&$ entsp $=a \& o e=U T F-8 \& i e=U T F-8 \& u d=1 \&$ site $=$ web_all\&filter $=0$ \&getfields $={ }^{\star}>$. Acesso em: 13 jan. 2011, às 15h19min.

SINDICATO DOS EMPREGADOS DO COMÉRCIO HOTELEIRO DE CAMPINAS E REGIÃO. Convenção Coletiva 2010/2012. Disponível em: <http://www.sinhotel.org.br/CCT\%20201012012. pdf $>$. Acesso em: 19 mar. 2012, às 15h17min.

SZAPIRO, M. Downgrading local capabilities in IT: the telecom innovation system in Campinas. In: CASSIOLATO, J.; LASTRES, H.; MACIEL, M. (Eds.). Systems of innovation and development: evidence from Brazil. Cheltenham: Edward Elgar, 2003.

THIOLLENT, M. Metodologia da pesquisa-ação. São Paulo: Cortez, 1985.

VILLASCHI, A. Anos 90: uma década perdida para o sistema nacional de inovação brasileiro?. São Paulo em Perspectiva, vol. 19, n.o 2, p. 3-20, abr./jun. 2005. 


\section{Apêndice}

\section{Tabela 1. Proposições da pesquisa de escala Likert}

1) No seu negócio, a procura por vagas disponíveis (garçom) ocorre com frequência?

2) O maior interesse dessa procura é para trabalho em período integral?

3) No seu negócio, a procura por vagas disponíveis (garçom) ocorre esporadicamente?

4) O maior interesse dessa procura é para trabalho em período parcial?

5) No seu negócio, a procura por vagas disponíveis (garçom) é um fator preocupante?

6) No seu negócio, a disponibilização de vagas (garçom) ocorre com frequência?

7) A maior necessidade das vagas disponibilizadas (garçom) é para trabalho em período integral?

8) No seu negócio, a disponibilização de vagas (garçom) ocorre esporadicamente?

9) A maior necessidade das vagas disponibilizadas (garçom) é para trabalho em período parcial?

10) No seu negócio, a disponibilização de vagas (garçom) é um fator preocupante?

11) No seu negócio, percebe-se que a força de trabalho (garçom) está mudando de trabalho em decorrência das novas oportunidades alternativas em outros setores?

12) No seu negócio, percebe-se que a força de trabalho (garçom) tem sido facilmente absorvida em outros setores, em decorrência da economia aquecida?

13) No seu negócio, percebe-se que a força de trabalho (garçom) tem tido melhores salários e benefícios em outros setores?

14) No seu negócio, percebe-se que as oportunidades alternativas à força de trabalho (garçom) em outros setores estão associadas a ritmos de trabalho mais atraentes, como folgas nos finais de semana?

17) No seu negócio, existem políticas de salários e benefícios destinados especificamente à força de trabalho (garçom)?

18) No seu negócio, os atuais salários e benefícios são suficientes para reter a força de trabalho (garçom)?

20) No seu negócio, o fator preço do cardápio ou serviço não tem influência direta na formação do salário da força de trabalho (garçom)?

21) No seu negócio, a gorjeta influencia diretamente a formação do salário da força de trabalho (garçom)?

29) No seu negócio, a força de trabalho (garçom) distingue a necessidade de trabalho, assim como a necessidade de lazer?

30) No seu negócio, a função exercida pela força de trabalho (garçom) é de fácil compreensão, aprendizagem, prática e transferência de conhecimento?

35) No seu negócio, o perfil da força de trabalho (garçom) está cada vez melhor, no que diz respeito a atribuições, atitudes e comportamento?

36) No seu negócio, a força de trabalho (garçom) adapta-se facilmente às regras de qualidade e eficiência exigidas?

37) No seu negócio, a jornada de trabalho influencia o desligamento da força de trabalho (garçom)?

38) O turismo de negócios é determinante para o funcionamento de seu negócio, e define, por sua vez, a estratégia de treinamento da força de trabalho (garçom)?

39) No seu negócio, investe-se constantemente em treinamento e desenvolvimento da força de trabalho (garçom)?

40) Quando em seu negócio necessita-se repor funcionários, contratar força de trabalho (garçom), essa ação representa preocupação e é facilmente praticada?

41) No seu negócio, a força de trabalho (garçom) distingue perfeitamente os clientes da região em relação aos turistas de negócios? 
42) No seu negócio, a força de trabalho (garçom) tem consciência da importância do turismo para a economia do município?

43) No seu negócio, as pesquisas com os clientes revelam satisfação nos serviços e no atendimento prestados pela força de trabalho (garçom)?

44) A força de trabalho (garçom) representa riscos relacionados com atrasos ou demora no atendimento aos clientes?

45) A força de trabalho (garçom) representa riscos relacionados com a possibilidade de erros no atendimento aos clientes?

46) Para o seu negócio, as instituições de ensino técnico ou superior exercem influência e papel importante na qualificação da força de trabalho (garçom)?

47) Para o seu negócio, as instituições de ensino técnico ou superior demonstram consciência da importância na capacitação da força de trabalho (garçom) em relação às novas necessidades?

48) Para o seu negócio, as instituições de ensino técnico ou superior são fundamentais na qualificação da força de trabalho (garçom) e, portanto, atendem às necessidades do negócio?

\section{Paulo Cesar Peres Pontara}

Organização / Instituição: FACCAMP / FACP / UNIP

Cargo / Titulação: MESTRE EM ADMINISTRACุÃO

CPF: 13740883820

Endereço Completo: RUA FLORIANO CAMARGO PENTEADO 365 APTO 13 / PONTE PRETA

Cidade: CAMPINAS / SP

CEP: $13041-470$

Telefone: (19) 9125-4747 / (19) 3232-2978

Email: pcperes@hotmail.com / pcperes2010@gmail.com

\section{Djair Picchiai}

Organização / Instituição: EAESP-FGV / FACCAMP

Cargo / Titulação: DOUTOR EM ADMINISTRAÇÃO

CPF: 672.476.878-00

Endereço Completo: RUA SÃO GALL, 485. VILA ANGLO BRASILEIRA

Cidade: SÃO PAULO /SP

CEP: 05054-170

Telefone: (11) 9192-4205

Email: djair.picchiai@fgv.br

\section{Tiago Zanett Albertini}

Organização / Instituição: USP / EMBRAPA

Cargo / Titulação: PÓS DOUTORANDO VETERINÁRIA

CPF: 702.286.981-20

Endereço Completo: RUA MALAVAZZI, 381

Cidade: PAULINIA /SP

CEP: $13140-000$

Telefone: (19) 3211-5838

Email: tiagoza@cnptia.embrapa.br albertinitz@gmail.com 